\title{
Subjective Health Assessment of Elderly Agricultural Worker
}

\author{
Min Tae Seo, Kyung Ran Kim, Hyo Cher Kim, Hye Seon Chae, \\ Kyung Doo Min, Yong Seok Shin, Kyung Suk Lee
}

National Academy of Agricultural Science, RDA, Suwon, 441-707

\begin{abstract}
Objective: The purpose of this study was to survey of the subjective health status of the elderly farmer. Background: With increase of aged population, the health of the elderly farmer has become main concerns of the elderly in the rural community. For the effects of the factors related to quality of life, subjective health condition showed the largest influence. Method: The survey was conducted by 326 elderly farmers aged 50 and older in rural areas through structured questionnaires. Survey questionnaire consisted items of general characteristics, health-related life habits, levels of stress(SF-PWI), symptom of musculoskeletal diseases and general level of health(SF-36). For the data analysis, SPSS 19.0K was used, and analysis was conducted by using frequency, percentage, mean, and standard deviation. For the symptom prevalence of musculoskeletal disorders and comparison of average level of health, chi-square test and $t$-test were used. Results: The results of the study are as follows. It was shown that the symptom prevalence of musculoskeletal disorders had a significant difference in gender $(p<0.01)$. Frequency analysis on presence of musculoskeletal symptoms in each part of body showed that leg $/$ knee region was $28.1 \%$, back region was $26.6 \%$, shoulder region was $18.0 \%$, arm/elbow region was $11.9 \%$, hand/wrist region was $8.2 \%$ and neck region was $7.2 \%$. According to comparison of average level of health, a social functioning were the highest as score 87.3, followed by mental health(65.6) and role limitation-emotional(65.5). Conclusion: Health promotion program for the elderly and female in the rural are needed. Application: The survey of the subjective health status of the elderly should be used for planning factors to make a health improvement plan in elderly farmer.
\end{abstract}

Keywords: Health, Elderly, Stress, Musculoskeletal disorders, Farmer

\section{Introduction}

농작업은 소수의 인원이 다양하고 과도한 작업을 수행해 야 하는 열악한 작업조건을 가지고 있고, 특히나 사회적 특 성상 농작업 인구의 고령화로 인하여 근골격계 질환과 같은 직업성 질환의 심각성이 다른 산업 분야에 비해 상당히 크다 고 예상할 수 있다. 또한 예측하기 어려운 작업환경과 자세
로 인하여 그 심각성은 날로 심화되고 있는 실정이다. 다른 측면으로는 농작업을 운영하는 농업인들의 경우, 사업자 단 체가 아닌 개인으로 대부분 운영되기 때문에 농작업으로 인 해 발생되는 재해 및 질병에 대한 실태 파악에 어려움이 있 다. 특히, 고령 농업인의 경우 농업인을 대상으로 시행되는 사회적 보상제도 또는 조사의 사각지대에 다수 분포되어 있 으므로 보다 적극적인 조사가 필요하다고 사료된다.

고령자 통계를 살펴보면, 2012년 총인구에서 65세 이상

Corresponding Author: Kyung Suk Lee. National Academy of Agricultural Science, RDA, Suwon, 441-707.

Mobile: +82-10-9903-1835, E-mail: leeks81@korea.kr

Copyright@2013 by Ergonomics Society of Korea(pISSN:1229-1684 eISSN:2093-8462). All right reserved.

(c) This is an open-access article distributed under the terms of the Creative Commons Attribution Non-Commercial License(http://creativecommons.org/licenses/by-nc/3.0/), which permits unrestricted non-commercial use, distribution, and reproduction in any medium, provided the original work is properly cited. http://www.esk.or.kr 
고령자가 차지하는 비중은 $11.8 \%$ 로 1970 년 $3.1 \%$ 에서 지 속적으로 증가하여 2030년 24.3\%, 2050년 37.4\% 수준에 이를 것으로 전망된다. 또한, 국내 농촌의 노인 인구 비율이 2001년 24.4\%에서 2006년 30.8\%로 증가하여 이미 초고 령화 사회로 접어들었으며 농촌의 노인 집중화 현상이 계속 심화되고 있는 실정이다. '2012 고령자통계'에서 도시와 농 어촌지역의 65 세 이상 고령자를 대상으로 생활 및 의식 차 이를 비교한 결과를 살펴보면, 자신의 건강상태가 나쁘다고 응답한 고령자는 농어촌지역이 $56.0 \%$ 로 도시지역 $46.3 \%$ 에 비해 $9.7 \%$ 더 높게 나타났으며, 운동을 규칙적으로 실 천한다고 응답한 비율도 농어촌지역의 고령자가 $23.8 \%$ 로 도시지역 고령자의 $43.7 \%$ 보다 더 낮은 것으로 나타났다 (Statistics Korea, 2012).

농촌의 경우 영농의 기계화가 이루어지면서 농업인이 직 접 수행하는 노동은 과거에 비하여 감소되고 있지만 농작업 시의 불편한 자세, 반복적인 동작, 그리고 과도한 힘의 사용 등에 기인하여 만성적인 농부증과 하우스증 등의 다양한 질 병이 현저하게 나타나고 있으며 (Park et al., 1994), 만성질 환 중 특히 가장 많은 부분을 차지하고 있는 근골격계 질환 의 경우는 다양한 연령에서 발생하고 의학적뿐만 아니라 사 회적인 관심에서도 건강관련 삶의 질의 중요성이 대두되고 있다(Jaeng, 2006).

건강과 생활만족도에 대한 연구를 살펴보면, 노인의 주관 적 건강상태가 나쁠수록 삶의 질이 낮은 것으로 나타났으며 삶의 질에 주관적 건강상태가 가장 큰 영향을 미치는 것으로 나타났다(Lee, 2010). 또한, 수입, 운동, 영양불량, 질환수, 심장질환, 뇌혈관질환, 낙상, 일상생활 수행능력, 도구적인 일상생활 수행능력, 우울증, 사회적 지원이 주관적 건강상태 와 유의한 관계를 보였다(Lee et al., 2002) 노인의 주관적 건강평가에 특히 질병과 신체적 - 정신적 기능상태가 중요한 영향을 미치는 것을 고려할 때 노인에 있어서 질병예방과 건 강증진이 중요함을 알 수 있다(Lee et al., 1998).

노인이 스스로 인식하는 건강의 구성 요소를 파악하는 과 정은 노인의 보건 - 복지 욕구수준을 유추해 볼 수 있다는 점에서 중요하다고 지적된다 $(\mathrm{Oh}, 2001)$. 또한, 주관적 건강 평가는 몇몇의 건강과 관련된 자료의 예측인자로서 광범위 하게 연구되어 의료이용률, 장애율 등의 강력한 예측인자로 알려져 있다(Miilunpalo et al., 1997; Farmer and Ferraro, 2010). 특히 정책기획 및 결정자가 유용하게 사용할 수 있 는 건강지표로 몇몇의 연구에서 건강상태를 부정적으로 평 가할수록 사망률이 증가하는 것을 보여주었다(Idler et al., 1991; MaCallumk et al., 1994; Idler et al., 1997; Bergner, 1985).

따라서, 본 연구는 농촌지역에 거주하는 고령 농업인을 대상으로 주관적 건강실태에 대해 조사하여 분석하고 이에
따른 결과를 고령 농업인의 신체기능을 고려한 정책적, 사회 적 개선의 기초자료로 제공하고자 한다.

\section{Method}

\subsection{Survey subjects}

본 연구의 조사 대상은 강원도 · 경기도 · 경상남도 · 경상 북도 · 충청북도 지역의 농작업 안전모델 시범마을 10 개 마 을에서 50세 이상 고령 농업인 326명을 대상으로 현장방문 을 통하여 조사하였다.

Table 1은 조사 대상자의 통계적 변인을 나타내고 있다. 조사결과 분석에서는 65세를 기준으로 준고령 농업인(50 64 세)과 고령 농업인(65세 이상)으로 정의하였고, 조사 대상자는 총 326명으로 남자 159명 (48.8\%), 여자 167명 (51.2\%)이였으며, 이 중 준고령자 107 명 $(32.8 \%)$, 고령자 219 명 $(67.2 \%)$ 이었다.

Table 1. Characteristics of survey subjects $(n=326)$

\begin{tabular}{c|c|c|c|c|c|c}
\hline \multirow{2}{*}{} & \multicolumn{2}{|c|}{ Male } & \multicolumn{2}{c|}{ Female } & \multicolumn{2}{c}{ All } \\
\cline { 2 - 7 } & Person & $\begin{array}{c}\text { Rate } \\
(\%)\end{array}$ & Person & $\begin{array}{c}\text { Rate } \\
(\%)\end{array}$ & Person & $\begin{array}{c}\text { Rate } \\
(\%)\end{array}$ \\
\hline Semi-aged & 53 & 33.3 & 54 & 32.3 & 107 & 32.8 \\
\hline Aged & 106 & 66.7 & 113 & 67.7 & 219 & 67.2 \\
\hline All & 159 & 48.8 & 167 & 51.2 & 326 & 100 \\
\hline $\begin{array}{c}\text { Mean(yr) } \\
\pm \text { S.D }\end{array}$ & \multicolumn{2}{|c|}{$68.8 \pm 7.6$} & \multicolumn{2}{|c|}{$68.3 \pm 6.8$} & \multicolumn{2}{c}{$68.5 \pm 7.2$} \\
\hline
\end{tabular}

\subsection{Survey method}

본 조사연구는 여러 조사원이 함께 수행하여야 하므로 설 문 및 면접조사에 대한 교육을 통하여 모든 조사원들 간에 연구목적 및 내용을 충분히 공유하였다. 조사방법에 대한 교 육은 조사원들 간의 차이로 야기될 수 있는 오차를 최소화하 기 위하여 예비조사를 수행 후 평가교육을 실시하고 설문 및 면접조사에 대한 방법을 서로 공유하며, 조사를 수행하는 동 안에도 정기적인 교육을 실시하였다.

\subsection{Research topic}

설문조사는 일반적 특성, 건강관련 생활습관, 스트레스 수 준, 근골격계 질환 증상조사, 일반적 건강수준 등에 대하여 조사하였다. 
건강관련 생활습관에서는 운동 - 흡연여부 및 알코올 의 존도에 대한 조사가 이루어졌다.

스트레스 수준평가는 일반인의 정신건강 수준의 측정을 위해 장세진의 PWI(Psychosocial Well-being Index)를 기초로 개발된 18 문항의 단축형 $\mathrm{SF}-\mathrm{PWI}$ 를 사용하였다. $\mathrm{SF}-\mathrm{PWI}$ 는 4점 척도(0-1-2-3)로 응답하도록 하였으며, 총점을 합하여 스트레스 수준을 측정하였다. 높은 점수는 스 트레스가 높음을 의미하며, 조사 대상자의 사회심리적 스트 레스의 실태를 파악하기 위하여 스트레스 점수를 기준에 따 라 0 8점까지를 건강군, 9 26점까지를 잠재적 스트레스군, 그리고 27점 이상을 고위험 스트레스군의 세 집단으로 구분 하여 주요 범주 별 분포를 분석하였다.

일반적 건강수준 측정조사 도구는 건강수준을 평가하기 위해 기능수준(functional status), 안녕수준(well-being), 전반적인 건강평가(overall evaluation of health) 등 3 개 영역으로 구분하여 조사하였다. 설문지 구성은 Table 2 와

Table 2. Levels of health(SF-36)

\begin{tabular}{|c|c|c|c|}
\hline \multicolumn{2}{|c|}{ Domain } & Division & $\begin{array}{c}\text { Question } \\
\text { number }\end{array}$ \\
\hline \multirow{9}{*}{$\begin{array}{l}\text { Level of } \\
\text { health }\end{array}$} & \multirow{4}{*}{$\begin{array}{c}\text { Functioning } \\
\text { level }\end{array}$} & Physical ability & 10 \\
\hline & & Social ability & 2 \\
\hline & & Role limitation physical & 4 \\
\hline & & Role limitation emotion & 3 \\
\hline & \multirow{3}{*}{$\begin{array}{c}\text { Stability } \\
\text { level }\end{array}$} & Mental health & 5 \\
\hline & & Vitality & 4 \\
\hline & & Pain & 2 \\
\hline & \multirow{2}{*}{$\begin{array}{c}\text { General health } \\
\text { assessment }\end{array}$} & General health & 5 \\
\hline & & Change in health & 1 \\
\hline
\end{tabular}

같으며, 9 개 하부영역의 총 36 문항으로 구성되어 있다.

근골격계 질환 증상조사는 증상조사표를 이용하여 신체 각 부위에 따라 증상유무, 증상빈도, 증상지속, 통증 정도 등 을 조사하였다. 근골격계 질환 유병률은 미국 국립산업안전 보건연구원(NIOSH)의 기준에 따라 구하였다. 증상의 유병 률은 다음과 같다.

- 증상 1 : 증상이 적어도 1 주일 이상 지속되거나 혹은 지 난 1 년간 1 달에 1 번 이상 증상이 발생하고 중간 통증 인 경우

- 증상 2: 증상이 적어도 1 주일 이상 지속되거나 혹은 지 난 1 년간 1 달에 1 번 이상 증상이 발생하고 심한 통증 이상인 경우

\section{Results}

고령 농업인을 대상으로 총 326 부의 설문지를 회수하여 자료의 통계처리 및 분석은 상용 통계 프로그램인 SPSS 19.0K for Windows를 활용하였다. 각 조사항목에 대한 분 석결과는 다음과 같다.

\subsection{Health-related life habits}

Table 3은 운동여부에 대한 결과이다. 조사 대상자의 운 동여부는 110명 $(33.7 \%)$ 이 건강을 위해서 운동을 하고 있 으나, 216명(66.3\%)은 일하느라 바빠서 130명(60.2\%), 몸이 불편해서 55 명 $(25.5 \%)$ 등의 이유로 운동을 하지 않는 것으로 나타났다. Table 4에서 흡연여부에 대한 결과를 보 면, 조사 대상자 중 비흡연자는 217 명 (66.6\%), 과거 흡연

Table 3. Exercise status $(n=326)$

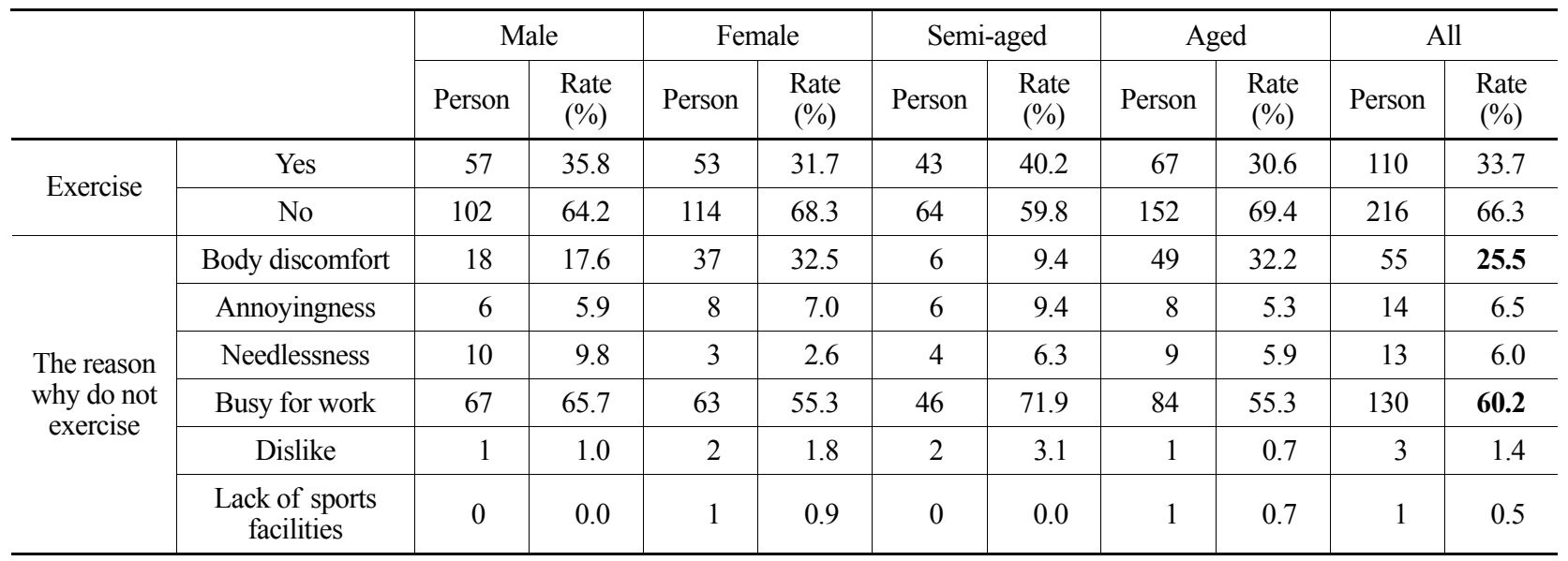


Table 4. Smoking status $(\mathrm{n}=326)$

\begin{tabular}{c|c|c|c|c|c|c|c|c|c|c}
\hline \multirow{2}{*}{} & \multicolumn{2}{|c|}{ Male } & \multicolumn{2}{c|}{ Female } & \multicolumn{2}{c|}{ Semi-aged } & \multicolumn{2}{c|}{ Aged } & \multicolumn{2}{c}{ All } \\
\cline { 2 - 13 } & Person & Rate(\%) & Person & Rate(\%) & Person & Rate $(\%)$ & Person & Rate(\%) & Person & Rate $(\%)$ \\
\hline Non-Smoker & 55 & 34.6 & 162 & 97.0 & 74 & 69.2 & 143 & 65.3 & 217 & 66.6 \\
\hline Past-Smoker & 53 & 33.3 & 3 & 1.8 & 11 & 10.3 & 45 & 20. & 56 & 17.2 \\
\hline Smoker & 51 & 32.1 & 2 & 1.2 & 22 & 20.6 & 31 & 14.2 & 53 & 16.2 \\
\hline
\end{tabular}

Table 5. Alcohol dependence $(n=139)$

\begin{tabular}{|c|c|c|c|c|c|c|c|c|c|c|}
\hline & \multicolumn{2}{|c|}{ Male } & \multicolumn{2}{|c|}{ Female } & \multicolumn{2}{|c|}{ Semi-aged } & \multicolumn{2}{|c|}{ Aged } & \multicolumn{2}{|c|}{ All } \\
\hline & Person & Rate(\%) & Person & Rate(\%) & Person & Rate(\%) & Person & Rate(\%) & Person & Rate(\%) \\
\hline Normal drinking & 58 & 58.0 & 37 & 94.9 & 32 & 58.2 & 63 & 75.0 & 95 & 68.3 \\
\hline Problem drinking & 14 & 14.0 & 0 & 0.0 & 6 & 10.9 & 8 & 9.5 & 14 & 10.1 \\
\hline Alcohol use disorder & 21 & 21.0 & 2 & 5.1 & 13 & 23.6 & 10 & 11.9 & 23 & 16.5 \\
\hline Alcohol dependence & 7 & 7.0 & 0 & 0.0 & 4 & 7.3 & 3 & 3.6 & 7 & 5.1 \\
\hline
\end{tabular}

Table 6. Levels of stress $(n=323)$

\begin{tabular}{|c|c|c|c|c|c|c|c|c|c|c|}
\hline & \multicolumn{2}{|c|}{ Male } & \multicolumn{2}{|c|}{ Female } & \multicolumn{2}{|c|}{ Semi-aged } & \multicolumn{2}{|c|}{ Aged } & \multicolumn{2}{|c|}{ All } \\
\hline & Person & Rate(\%) & Person & Rate(\%) & Person & Rate(\%) & Person & Rate(\%) & Person & Rate(\%) \\
\hline Health group & 33 & 21.0 & 17 & 10.2 & 24 & 22.6 & 26 & 12.0 & 50 & 15.5 \\
\hline Potential stress group & 92 & 58.6 & 91 & 54.8 & 59 & 55.7 & 124 & 57.1 & 183 & 56.7 \\
\hline Stress high-risk group & 32 & 20.4 & 58 & 34.9 & 23 & 21.7 & 67 & 30.9 & 90 & 27.9 \\
\hline
\end{tabular}

을 하였으나 현재 금연상태인자는 56명 (17.2\%)이었고, 현 재 흡연자는 53명 $(16.2 \%)$ 로 나타났다.

Table 5는 알코올 의존도에 대한 결과이다. 알코올 의존 도 문항에 응답한 139 명 중 성별, 고령자 구분으로 보았을 때 남성의 $42.0 \%$ 정도가 문제음주 이상의 알코올 의존도를 보임을 알 수 있다. 반면 여성은 문제음주 이상의 비율이 약 $5.1 \%$ 대에 불과하여 남성의 음주문화에 문제가 심각함을 알 수 있다. 또한, 준고령자 문제음주 이상의 비율은 $41.8 \%$, 고 령자 문제음주 이상의 비율은 $25.0 \%$ 로 준고령자의 문제음 주자 비율이 고령자에 비해 높음을 수 있다.

\subsection{Levels of stress(SF-PWI)}

Table 6은 조사 대상자의 스트레스 수준에 대한 결과이 다. 조사 대상자 326 명 중 스트레스 수준평가 문항에 응답 한 323 명 이었다. 스트레스 수준은 일반적으로 8점 이하는 정상군, 9 26점은 스트레스 잠재군, 27점 이상은 고위험군 으로 평가하는데 본 조사에서 정상군이 50명 $(15.5 \%)$ 에 불 과해 대부분의 농업인이 스트레스를 받고 있는 것으로 조사
되었다. 스트레스 잠재군의 경우는 183 명 $(56.7 \%)$ 으로 가장 높게 나타났고, 고위험군의 경우도 90 명 (27.9\%)으로 정상 군보다 높게 나타났다.

\subsection{Survey on symptom of musculoskeletal diseases}

Table 7은 근골격계 질환 유병률에 대한 결과이다. 근골 격계 질환 증상조사표를 이용하여 지난 1 년 동안 농사일과 관련된 근골격계 질환에 대하여 조사한 결과 정상자 93 명 (28.5\%), 증상1의 경우가 95명 $(29.2 \%)$, 증상 2 는 138 명 (42.3\%)으로 증상1 이상의 통증을 호소하는 사람이 233명 (71.5\%)으로 높은 비율을 보였다. 증상 2 에 대하여 성별로 비교해 보았을 때 남성은 $32.7 \%$ 에 반해 여성은 $51.5 \%$ 로 남성 증상 2 의 비율이 여성에 비해 매우 높음을 알 수 있다. 근골격계 질환 유병률에 따라 성별로 비교하였을 경우 여성 이 남성에 비해 유병률이 높으며 통계적으로도 유의하였다 $(p<0.01)$.

신체부위별 근골격계 질환 증상유무는 다리/무릎 $(28.1 \%)$, 허리 (26.6\%) 및 어깨(18.0\%)가 가장 많았다. 성별 및 고 
Table 7. Symptom prevalence of musculoskeletal disorders $(\mathrm{n}=326)$

\begin{tabular}{|c|c|c|c|c|c|c|c|c|c|c|}
\hline & \multicolumn{2}{|c|}{ Male } & \multicolumn{2}{|c|}{ Female } & \multicolumn{2}{|c|}{ Semi-aged } & \multicolumn{2}{|c|}{ Aged } & \multicolumn{2}{|c|}{ All } \\
\hline & Person & Rate(\%) & Person & Rate(\%) & Person & Rate(\%) & Person & Rate(\%) & Person & Rate(\%) \\
\hline Normal & 57 & 35.8 & 36 & 21.6 & 23 & 21.5 & 70 & 32.0 & 93 & 28.5 \\
\hline Symptom 1 & 50 & 31.4 & 45 & 26.9 & 37 & 34.6 & 58 & 26.5 & 95 & 29.2 \\
\hline Symptom 2 & 52 & 32.7 & 86 & 51.5 & 47 & 43.9 & 91 & 41.5 & 138 & 42.3 \\
\hline$p$-value(Chi-square test) & \multicolumn{4}{|c|}{$.001^{* *}$} & \multicolumn{4}{|c|}{.107} & \multicolumn{2}{|c|}{-} \\
\hline
\end{tabular}

Table 8. Musculoskeletal disorders by body part

\begin{tabular}{|c|c|c|c|c|c|c|c|c|c|c|}
\hline & \multicolumn{2}{|c|}{ Male } & \multicolumn{2}{|c|}{ Female } & \multicolumn{2}{|c|}{ Semi-aged } & \multicolumn{2}{|c|}{ Aged } & \multicolumn{2}{|c|}{ All } \\
\hline & Person & Rate(\%) & Person & Rate(\%) & Person & Rate(\%) & Person & Rate(\%) & Person & Rate(\%) \\
\hline Neck & 13 & 6.6 & 22 & 7.6 & 14 & 7.4 & 21 & 7.0 & 35 & 7.2 \\
\hline Shoulder & 35 & 17.8 & 53 & 18.2 & 35 & 18.6 & 53 & 17.7 & 88 & 18.0 \\
\hline Arm/Elbow & 25 & 12.7 & 33 & 11.3 & 28 & 14.9 & 30 & 10.0 & 58 & 11.9 \\
\hline Hand/Palm & 15 & 7.6 & 25 & 8.6 & 19 & 10.1 & 21 & 7.0 & 40 & 8.2 \\
\hline Waist & 59 & 29.9 & 71 & 24.4 & 50 & 26.6 & 80 & 26.7 & 130 & 26.6 \\
\hline Leg/Knee & 50 & 25.4 & 87 & 29.9 & 42 & 22.3 & 95 & 31.7 & 137 & 28.1 \\
\hline
\end{tabular}

Table 9. Comparison of average level of health

\begin{tabular}{c|c|c|c|c|c|c|c}
\hline & Male & Female & $\begin{array}{c}p \text {-value } \\
(t \text {-test })\end{array}$ & Semi-aged & Aged & $\begin{array}{c}p \text {-value } \\
(t \text {-test })\end{array}$ & All \\
\hline General health & $53.4(20.4)$ & $40.5(20.7)$ & $.000^{* *}$ & $48.5(23.0)$ & $45.9(20.8)$ & .322 & $46.7(21.5)$ \\
\hline Physical ability & $70.7(26.3)$ & $53.5(28.3)$ & $.000^{* *}$ & $71.2(26.0)$ & $57.3(28.8)$ & $.000^{* *}$ & $61.8(28.6)$ \\
\hline Role limitation physical & $44.9(41.7)$ & $26.2(36.4)$ & $.000^{* *}$ & $44.8(39.0)$ & $30.7(39.9)$ & $.003^{* *}$ & $35.3(40.1)$ \\
\hline Role limitation emotion & $68.6(43.6)$ & $62.5(44.4)$ & .214 & $70.8(40.2)$ & $62.9(45.6)$ & .113 & $65.5(44.0)$ \\
\hline Social skill & $90.4(15.2)$ & $84.4(21.4)$ & $.004^{* *}$ & $88.6(17.5)$ & $86.7(19.5)$ & .387 & $87.3(18.9)$ \\
\hline Pain & $61.4(32.7)$ & $44.4(28.0)$ & $.000^{* *}$ & $55.8(30.1)$ & $51.1(32.1)$ & .206 & $52.6(31.5)$ \\
\hline Vitality & $45.7(20.2)$ & $36.9(18.9)$ & $.000^{* *}$ & $45.0(21.8)$ & $39.3(18.9)$ & $.018^{*}$ & $41.1(20.0)$ \\
\hline Mental health & $70.5(19.3)$ & $61.1(20.6)$ & $.000^{* *}$ & $67.0(21.4)$ & $64.9(20.1)$ & .386 & $65.6(20.5)$ \\
\hline
\end{tabular}

Average $( \pm$ S.D $), *: p<0.05, * *: p<0.01$

령자 구분으로 비교하면 남성은 허리 $(29.9 \%)$, 여성은 다리 /무릎 $(29.9 \%)$, 준고령자는 허리(26.6\%), 고령자는 다리/무 릎 $(31.7 \%)$ 에서 높게 나타났다. 이러한 결과는 앞서 작업형 태 결과에서 알 수 있듯이 남성의 경우 '허리를 많이 숙이거 나 비틀어서 하는 작업'의 비율이 높고, 여성의 경우 '쪼그리 거나 무릎을 껋는 작업'의 비율이 높은 데서 나오는 결과로 보여진다. 또한, 준고령자의 유병률 $(38.5 \%)$ 보다 고령자의 유병률 $(61.5 \%)$ 이 매우 높게 나타났으며, 고령자의 경우 다 리/무릎의 유병률이 $31.7 \%$ 로 가장 높으므로 고령자의 건강 관리 및 이동수단을 개발하여 지원해 줄 필요성이 있다고 보
여진다(Table 8).

\subsection{General level of health(SF-36)}

Table 9는 건강수준에 대한 항목별 평균 비교 결과이다. 남성과 여성의 건강수준을 보았을 때, 남성 (53.4 \pm 20.4$)$ 이 여성 (40.5 \pm 20.7$)$ 에 비해 높게 나타났으며, 통계적으로 유 의한 차이가 있었다 $(p<0.01)$. 남성과 여성 사이에 세부항 목별로 보았을 때 모든 항목에서 남성이 여성보다 항목별 건강수준이 높게 나타났으며, 감정적 역할제한을 제외한 모 
든 항목에서 통계적으로 유의한 차이를 보였다 $(p<0.01)$. 준 고령과 고령자 건강수준 비교에서는 모든 세부항목에서 준 고령자의 건강수준이 고령자의 건강수준 보다 높게 나타났 다. 통계적 분석 결과 신체적 기능 $(p<0.01)$, 신체적 역할제 한 $(p<0.01)$, 활력 $(p<0.05)$ 항목에서 유의한 차이를 보였 으나, 일반적 건강, 감정적 역할제한, 통증, 정신건강 항목에 서 준고령자와 고령자 사이에 유의한 차이가 없었다.

\section{Conclusion}

본 연구는 5 개 지역 10 개 마을에서 50 세 이상 고령 농업 인을 대상으로 주관적 건강실태 조사를 실시하여 다음과 같 은 결론을 얻었다.

첫째, 조사 대상자의 운동여부는 110 명 $(33.7 \%)$ 이 건강을 위해서 운동을 하고 있으나, 216 명 $(66.3 \%)$ 은 일하느라 바 빠서 130명 (60.2\%), 몸이 불편해서 55명 $(25.5 \%)$ 등의 이 유로 운동을 하지 않는 것으로 나타났고, 비흡연자는 217 명 $(66.6 \%)$, 현재 금연상태인자는 56명 $(17.2 \%)$ 이었고, 현재 흡연자는 53명 (16.2\%)로 나타났다. 알코올 의존도에서는 남성의 $42.0 \%$ 가 문제음주 이상의 알코올 의존도를 보인 반 면 여성은 문제음주 이상의 비율이 약 $5.1 \%$ 대에 불과하여 남성의 음주문화에 문제가 심각함을 알 수 있다.

둘째, 고령 농업인의 스트레스 수준평가 결과 스트레스 잠 재군의 경우는 183 명 $(56.7 \%)$ 으로 가장 높게 나타났고, 고 위험군의 경우도 90 명 $(27.9 \%)$ 으로 정상군보다 높게 나타 났다. 반면 스트레스 응답자 중 정상군이 50명 (15.5\%)에 불과해 대부분의 농업인이 스트레스를 받고 있는 것으로 조 사되었다.

셋째, 근골격계 질환 증상조사를 통해 근골격계 질환 유병 률에 대한 차이를 분석한 결과, 성별에 따라 근골격계 질환 유병률은 매우 유의한 차이를 보였다 $(p<0.01)$. 또한 50세 이상 고령 농작업자의 $71.5 \%$ 가 근골격계 질환에 대한 관리 가 필요하다고 판단되며, 다리/무릎, 허리, 어깨 신체부위에 서 통증 호소자가 높은 빈도를 보였다.

넷째, 건강수준에 대한 항목별 평균을 분석한 결과, 남성 이 여성보다 모든 건강수준 조사항목에서 건강수준이 높게 평가되었으며, 준고령자 또한 모든 조사항목에서 고령자보다 높은 건강수준을 보였다. 남성과 여성은 감정적 역할제한을 제외한 모든 항목에서 통계적으로 유의한 차이를 보였으며 $(p<0.01)$, 준고령자와 고령자에서는 신체적 기능 $(p<0.01)$, 신체적 역할제한 $(p<0.01)$, 활력 $(p<0.05)$ 항목에서 유의한 차이를 보였다.

본 연구의 결과는 고령 농업인의 보건 · 복지 및 고령자
건강실태 파악의 기초자료로 활용될 것으로 기대되며, 향후 고령 농업인 스스로 인지하는 주관적 건강에 영향을 미치는 요인에 대한 정확한 파악을 통해 노인의 건강수준을 향상시 킬 수 있는 정책적, 사회적 지원이 필요한 것으로 사료된다.

\section{Acknowledgements}

This study was carried out with the support of "Research Program for Agricultural Science \& Technology Development (Project No. PJ008420)", National Academy of Agricultural Science, Rural Development Administration, Republic of Korea.

\section{References}

Bergner, M., Measurement of health status, Med Care, 23(5), 696-704, 1985. Farmer, M.M. and Ferraro, K.F., Distress and perceived health: mechanism of health decline, Journal Health Soc Behav, 38(3), 298-311, 1997.

Lee, D.H., The effects of quality of life in the elderly's health condition, Journal of the Korean Gerontological Society, 30(1), 93-108, 2010.

Idler, E.L. and Benyamini Y., Self-rated health and mortalithy: a review of twenty-seven community studies, Journal Health Soc Behav, 38(1), 21-37, 1997.

Idler, E.L. and Kasl, S., Health perceptions and survival: do global evalution of Health status really predict mortality, Journal Gerontol, 46(2), 55 $-65,1991$.

Jaeng, J.S., A Study on Chronic Patients Life Quality, Graduate School of Kyung-Hee University, 2006.

Lee, Y.H., Choi, K.S., Kang, I.O. and Kim, H.J., Determinants of SelfRated Health Among the Korean Elderly Living in the Community, Journal of the Korean Gerontological Society, 18(2), 110-124, 1998.

Lee, H.J., Chung, Y.J., Kim, H.J., Suh, H.S., Lee, H.S., Shim, K.W., Lee, S.H. and Cho, C.Y., Determinants of Self-assessed Health among Elderly Adults, Korean Journal of Family Medicine, 23(10), 1210 $-1218,2002$.

Lee, DH., The Effects of Quality of Life in te Elderly's Health Condition, Journal of the Korean Gerontological Society, 30(1), 93-108, 2010.

National Institute for Occupational Safety and Health(NIOSH).

Miilunpalo, S., Vuori, I., Oja, P., Pasanen M. and Urponen, H., Self-rated health status as a health measuer: The predictive value of self-reported health status on the use of physician services and on mortality in the working-age population, Journal Clin Epidermiol, 50(5), 517-528, 1997.

MaCallumk, J., Shadbolt, B. and Wang, D., Self-rated health and survival: a 7-year follow-up study of Australian elderly, Am Journal Public Health, 84(7), 1100-1105, 1994. 
Statistics Korea, Statistics on the Age, 2012.

Oh, Y.H., A Study on Self-Rated Health of Elderly, Journal of the Korean Gerontological Society, Symposium in Autumn, 2001.

Park, T.J., Kim, B.S. and Chon, H.J., Factors Associated with Farmers' Syndrome, Korean journal of rural medicine, 19(1):5-13, 1994.

\section{Author listings}

Min Tae Seo: smt850920@skku.edu

Highest degree: MS, Department of Industrial Engineering, Sungkyunkwan University

Position title: Researcher, Department of Agricultural Engineering, National Academy of Agricultural Science, RDA, Suwon

Areas of interest: Physical ergonomics, Occupational Safety \& Health, WMSDs, Hand tools

\section{Kyung Ran Kim: kimgr@korea.kr}

Highest degree: $\mathrm{PhD}$, Department of Clothing \& Textile, Seoul National University

Position title: Senior Researcher, Department of Agricultural Engineering, National Academy of Agricultural Science, RDA, Suwon

Areas of interest: Musculoskeletal workload, work condition,

Agricultural Safety \& Health

Hyo Cher Kim: hyocher@me.com

Highest degree: MPH, Department of Public health, Seoul National University

Position title: Researcher, Department of Agricultural Engineering, National Academy of Agricultural Science, RDA, Suwon

Areas of interest: Industrial Hygiene
Hye Seon Chae: hyeseon@korea.kr

Highest degree: MS, Department of Clothing Textile, Yeungnam University

Position title: Researcher, Department of Agricultural Engineering, National Academy of Agricultural Science, RDA, Suwon

Areas of interest: Agriculture, Agricultural Safety \& Health

Kyung Doo Min: m2nk0doo@wku.ac.kr

Highest degree: MS, Department of Information Statistics, Won-Kwang University

Position title: Researcher, Department of Agricultural Engineering, National Academy of Agricultural Science, RDA, Suwon Areas of interest: Statistics, Agricultural Safety \& Health

Yong Seok Shin: yshin838@gmail.com

Highest degree: MS, Department of Industrial Management Engineering, Dong-Eui University

Position title: Researcher, Department of Agricultural Engineering, National Academy of Agricultural Science, RDA, Suwon

Areas of interest: Ergonomics, Occupational Safety \& Health,

Kyung Suk Lee: leeks81@korea.kr

Highest degree: $\mathrm{PhD}$, Department of Clothing Textile, Seoul National University

Position title: Senior Researcher, Department of Agricultural Engineering, National Academy of Agricultural Science, RDA, Suwon

Areas of interest: Agriculture, Agricultural Safety \& Health

Date Received : 2013-11-13

Date Revised :2013-11-14

Date Accepted : 2013-11-14 